\title{
PRELIMINARY DETERMINATION OF THE JET-2 UNMANNED AERIAL VEHICLE DYNAMIC PERFORMANCES
}

\author{
Grzegorz Kowaleczko \\ Air Force Institute of Technology \\ Ksiecia Boleslawa Street 6, 01-494 Warsaw, Poland \\ tel.: +4822 6851111, fax: +48228364471 \\ e-mail: grzegorz.kowaleczko@itwl.pl
}

\begin{abstract}
The paper presents result of theoretical analysis of the spatial dynamic performances for an unmanned aerial vehicle (UAV). This drone is designed and produced by consortium consisted of The Air Force Institute of Technology, The Military University of Technology, The Warsaw University of Technology and The MSP enterprise. A plane JET-2 is the jet-powered airplane dedicated for Polish Military Forces. It will be used in the training process of anti-aircraft crews. Because of high level of requirements (maximum speed, stall speed, climb rate, range and endurance), it has been designed as the jet-powered aircraft. This plane will perform autonomous flights and therefore it should be stable in all phases of flight - static and dynamic stability is desirable. Therefore, the theoretical analysis focused on the stability performances have been performed, parallel to laboratory tests. They were done using nonlinear mathematical model of the JET-2. This model will be described in the paper as well as selected results of numerical simulations.

The UAV JET-1 parameters and main parts of the system with the performances as the take-off mass $80 \mathrm{~kg}$, the maximum speed $150 \mathrm{~m} / \mathrm{s}$, the endurance $60 \mathrm{~min}$, the altitude $5000 \mathrm{~m}$ are presented in the paper.
\end{abstract}

Keywords: unmanned aerial vehicle, JET-2 plane, aerodynamic characteristics, dynamic performances

\section{Introduction}

The Air Force Institute of Technology (AFIT) is one of the main Polish scientific centres developing the unmanned aerial vehicle technologies. For many years, a lot of various UAVs have been being designed and produced by AFIT. One of the more important directions of this effort is the aerial target systems (ATS). Most of them were based of the propeller-powered planes but six year ago, the new generation of ATS was investigated. As the result of this work, the system based on a jet-powered drone was built. This UAV JET-1 has the following parameters:

- the mass $42 \mathrm{~kg}$,

- the maximum speed $100 \mathrm{~m} / \mathrm{s}$,

- the endurance $45 \mathrm{~min}$,

- the altitude 200-2500 m.

Nowadays next jet-powered UAV target system is under construction. The main part of this system will be consisting of five drones (Fig. 1) with the following performances:

- the take-off mass $80 \mathrm{~kg}$,

- the maximum speed $150 \mathrm{~m} / \mathrm{s}$,

- the endurance $60 \mathrm{~min}$,

- the altitude $5000 \mathrm{~m}$.

The two jet engines plane will be taken off with the pneumatic catapult. It will be equipped with parachute recovery/emergency system. The plane is designed to autonomous flights. Therefore, an autopilot system is one of the more important avionic systems. For correct operation of the autopilot, the knowledge about dynamic properties of the plane is necessary. This knowledge may be achieved experimentally or by theoretical calculations using mathematical model of the spatial motion of the JET-2 plane. This model is presented below. 


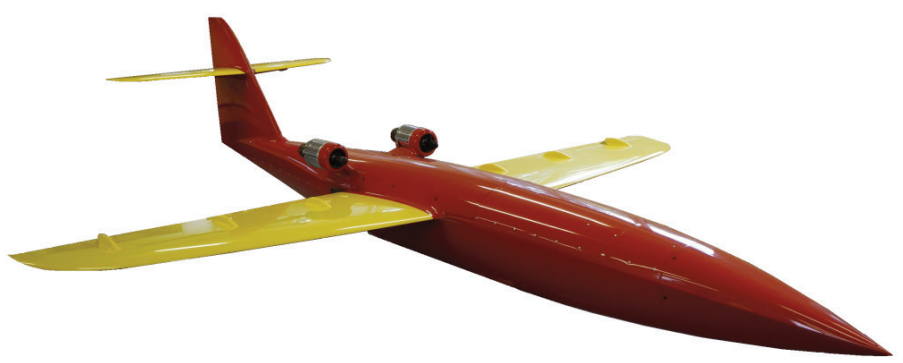

Fig. 1. The JET-2 plane

\section{Equations of the Problem}

Let us consider an aircraft spatial motion. The equations of its motion and kinematic relations will be expressed making use of moving coordinate systems, the common origin of which is located at the centre of mass of the aircraft (Fig. 2 and 3).

We shall apply a vertical moving system of coordinates $O x_{g} y_{g} z_{g}$, the $O z_{g}$ axis of which is vertical and directed downwards, a system of coordinates $O x y z$ attached to the aircraft (body axes), where the $O x z$ plane coincides with the symmetry plane of the aircraft, and a system $O x_{a} y_{a} z_{a}$ attached to the air trajectory (velocity axes), in which the $O x_{a}$ axis is directed along the flight velocity vector $\boldsymbol{V}$ and the $O z_{a}$ axis lies in the symmetry plane of the aircraft directed downwards.

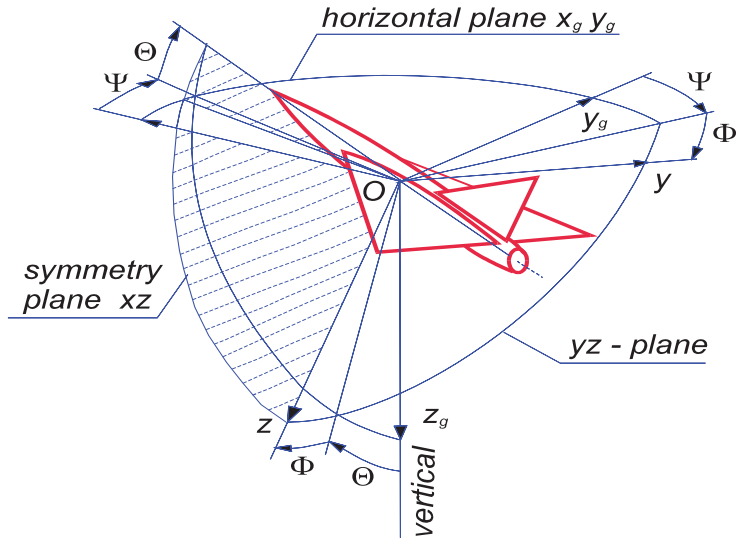

Fig. 2. Oxgygzg and Oxyz coordinate systems

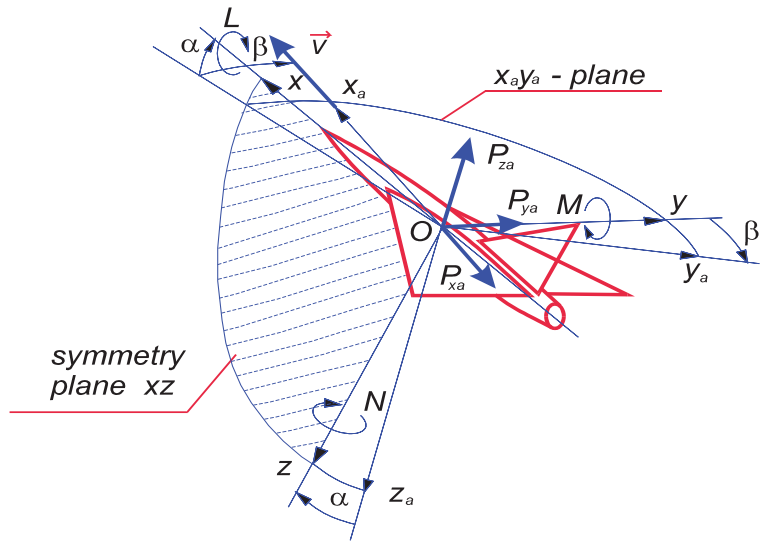

Fig. 3. Oxayaza and Oxyz coordinate systems

The relative position of the vertical system $O x_{g} y_{g} z_{g}$ and the body system $O x y z$, attached to the aircraft is described by Euler angles $\Theta, \Phi$ and $\Psi$ (Fig. 2), while the relative position of the system $O x y z$ and the system $O x_{a} y_{a} z_{a}$ attached to the air trajectory - by the angle of attack $\alpha$ and the angle of sideslip $\beta$ (Fig. 3).

The equations of motion of the centre of mass in the velocity system of coordinates can be obtained in the following form (cf. $[2-4,7])$ :

$$
\left\{\begin{aligned}
\frac{d V}{d t}= & \left\{\left[T \cos \left(\alpha+\phi_{s}\right)-m g(\sin \Theta \cos \alpha-\cos \Theta \cos \Phi \sin \alpha)\right] \cos \beta+\right. \\
& +m g\left(\cos \Theta \sin \Phi \sin \beta-P_{X a}\right\} / m, \\
\frac{d \alpha}{d t} & =q-(p \cos \alpha+r \sin \alpha) \tan \beta-\left[T \sin \left(\alpha+\phi_{s}\right)-\right. \\
& \left.-m g(\sin \Theta \sin \alpha+\cos \Theta \cos \Phi \cos \alpha)+P_{Z a}\right] / m V \cos \beta, \\
\frac{d \beta}{d t} & =p \sin \alpha-r \cos \alpha-\left\{\left[T \cos \left(\alpha+\phi_{s}\right)-m g(\sin \Theta \cos \alpha-\right.\right. \\
& \left.-\cos \Theta \cos \Phi \sin \alpha)] \sin \beta-m g \cos \Theta \sin \Phi \cos \beta-P_{Y a}\right\} / m V .
\end{aligned}\right.
$$


The set of equations of the rotating motion about the centre of mass in the body-fixed reference frame is:

$$
\left\{\begin{array}{l}
I_{X} \frac{d p}{d t}+\left(I_{Z}-I_{Y}\right) q r-I_{X Z}\left(\frac{d r}{d t}+p q\right)=L_{C}, \\
I_{Y} \frac{d q}{d t}+\left(I_{X}-I_{Z}\right) p r+I_{X Z}\left(p^{2}-r^{2}\right)=M_{C}, \\
I_{Z} \frac{d r}{d t}+\left(I_{Y}-I_{X}\right) p q-I_{X Z}\left(\frac{d p}{d t}-q r\right)=N_{C}
\end{array}\right.
$$

The equations of motion (2.1), (2.2) should be completed by the following kinematic relations, which enable us to determine the angular position of the aircraft with reference to the system of coordinates $O x_{g} y_{g} z_{g}$ (Fig. 1).

$$
\begin{aligned}
& \dot{\Psi}=(r \cos \Phi+q \sin \Phi) / \cos \Theta, \\
& \dot{\Theta}=q \cos \Phi-r \sin \Phi, \\
& \dot{\Phi}=p+(q \sin \Phi+r \cos \Phi) \tan \Theta
\end{aligned}
$$

and the relations for determining the position of the centre of mass in the fixed coordinate:

$$
\begin{gathered}
\frac{d x_{g}}{d t}=u \cos \Theta \cos \Psi+v(\sin \Theta \sin \Phi \cos \Psi-\cos \Phi \sin \Psi)+w(\sin \Theta \cos \Phi \cos \Psi+\sin \Phi \sin \Psi) \\
\frac{d y_{g}}{d t}=u \cos \Theta \sin \Psi+v(\sin \Theta \sin \Phi \sin \Psi+\cos \Phi \cos \Psi)+w(\sin \Theta \cos \Phi \sin \Psi-\sin \Phi \cos \Psi) \\
\frac{d z_{g}}{d t}=-u \sin \Theta+v \cos \Theta \sin \Phi+w \cos \Theta \cos \Phi
\end{gathered}
$$

The velocity components in the reference frame attached to the aircraft can be found from the equations (Fig. 3):

$$
\begin{aligned}
u & =V \cos \alpha \cos \beta, \\
v & =V \sin \beta, \\
w & =V \sin \alpha \cos \beta .
\end{aligned}
$$

The aerodynamic forces in the velocity coordinates can be expressed in the form:

$$
\begin{aligned}
P_{X_{a}} & =\frac{1}{2} \rho V^{2} S C_{D}, \\
P_{Y_{a}} & =\frac{1}{2} \rho V^{2} S C_{Y}, \\
P_{Z_{a}} & =\frac{1}{2} \rho V^{2} S C_{L},
\end{aligned}
$$

and the components of the moment of forces in the right-hand members of Eq. (2.2) are:

$$
\begin{aligned}
L_{C} & =L+L_{e}+L_{g}, \\
M_{C} & =M+M_{e}+M_{g}, \\
N_{C} & =N+N_{e}+N_{g},
\end{aligned}
$$

where $L_{e}, M_{e}, N_{e}$ are components of the engine thrust moment, $L_{g}, M_{g}, N_{g}$ are components of the gyroscopic moment of the rotating masses of the power plant and $L, M, N$ are the roll, pitch and yaw components of the aerodynamic moment of the aircraft: 


$$
\begin{aligned}
L & =\frac{1}{2} \rho V^{2} S l C_{l}, \\
M & =\frac{1}{2} \rho V^{2} S b_{a} C_{m}, \\
N & =\frac{1}{2} \rho V^{2} S l C_{n} .
\end{aligned}
$$

\section{Identification of aerodynamic characteristics}

Coefficients of aerodynamic forces - that is the coefficient of drag $C_{D}$, the coefficient of lateral force $C_{Y}$, the coefficient of lift $C_{L}$, and coefficients of aerodynamic moments, the rolling moment coefficient $C_{l}$, the pitching moment coefficient $C_{m}$, the yawing moment coefficient $C_{n}$ and their derivatives have been determined for the JET-2 making use of the results of theoretical calculations (cf. [3-6]) performed with the software Advanced Aircraft Analysis ver3.2 [1]. These calculations are based on the reconstructed geometry data of the aircraft shown in Fig. 4.

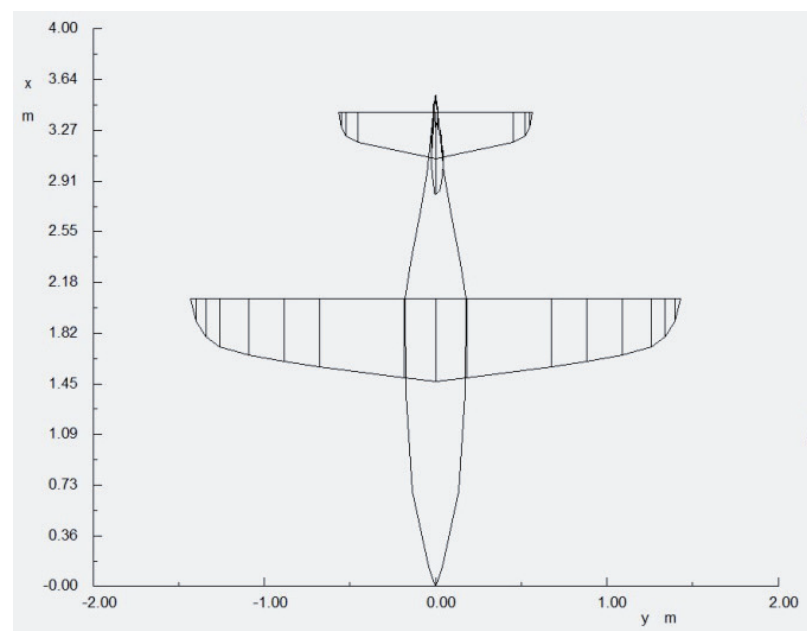

\begin{tabular}{|c|c|c|c|c|c|c|c|c|c|c|c|c|c|c|c|}
\hline \multicolumn{16}{|c|}{ Output Parameters } \\
\hline$\varepsilon_{h}$ & 0.85 & deg & ? $\mathrm{C}_{\mathrm{T}_{\mathrm{T}}}$ & & $\mathrm{rad}^{-1}$ & ? & 0.0220 & $\operatorname{rad}^{-1}$ & $\begin{array}{ll}3 \\
4\end{array}$ & -0.8929 & $\mathrm{rad}^{-1}$ & $\frac{?}{4} \mathrm{C}_{\mathrm{h}_{\mathrm{v}}}$ & & $\mathrm{rad}^{-1}$ & $\frac{?}{4}$ \\
\hline$\eta_{h_{p . \text { off }}}$ & 1.000 & & $\frac{?}{4} \mathrm{C}_{\mathrm{D}_{\alpha}}$ & 0.0000 & $\mathrm{rad}^{-1}$ & ? $\mathrm{C}_{y_{p}}$ & 0.0150 & $\mathrm{rad}^{-1}$ & $\mathrm{C}_{\mathrm{m}_{\mathrm{e}}}$ & -0.5830 & $\mathrm{rad}^{-1}$ & $\mathrm{C}_{\mathrm{h}_{\sigma_{\mathrm{r}}}}$ & & $\mathrm{rad}^{-1}$ & $\frac{?}{4}$ \\
\hline$\eta_{\mathrm{h}}$ & 1.000 & & $C_{L_{\alpha}}$ & 1.7909 & $\mathrm{rad}^{-1}$ & $\frac{?}{4} C_{1}$ & -0.4132 & $\operatorname{rad}^{-1}$ & $\frac{1}{4} C_{h_{\alpha}}$ & & $\mathrm{rad}^{-1}$ & $\frac{2}{4}$ & 0.0000 & $\mathrm{rad}^{-1}$ & $\frac{2}{4}$ \\
\hline $\mathrm{C}_{\mathrm{T}_{\mathrm{x}_{1}}}$ & 0.0000 & & $\frac{2}{4} \mathrm{C}_{m_{\alpha}}$ & -4.7174 & $\mathrm{rad}^{-1}$ & $\mathrm{C}_{n}$ & -0.0238 & $\mathrm{rad}^{-1}$ & & | & $\mathrm{rad}^{-1}$ & & 0.1212 & $\mathrm{rad}^{-1}$ & $\frac{?}{?}$ \\
\hline $\mathrm{C}_{\mathrm{m}_{\mathrm{T}_{1}}}$ & 0.0000 & & ? $\mathrm{C}_{\mathrm{Q}}$ & 0.0000 & $\mathrm{rad}^{-1}$ & ? $C_{y_{r}}$ & 0.4074 & $\mathrm{rad}^{-1}$ & \begin{tabular}{l|l}
$?$ \\
\\
4
\end{tabular} & $\mid-0.3727$ & $\mathrm{rad}^{-1}$ & $\frac{?}{4}$ & & $\mathrm{rad}^{-1}$ & $\frac{?}{4}$ \\
\hline $\mathrm{C}_{\mathrm{D}_{\mathrm{u}}}$ & 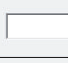 & & $\stackrel{?}{a} \mathrm{C}_{\mathrm{L}_{\mathrm{q}}}$ & 7.0393 & $\mathrm{rad}^{-1}$ & ? & 0.0728 & $\mathrm{rad}^{-1}$ & ? & -0.0257 & $\mathrm{rad}^{-1}$ & & & $\mathrm{rad}^{-1}$ & $\frac{?}{4}$ \\
\hline $\mathrm{C}_{\mathrm{Lu}_{u}}$ & 0.0086 & & $\frac{?}{\mathrm{C}_{\mathrm{m}}}$ & -12.3311 & $\mathrm{rad}^{-1}$ & $\mathrm{C}_{\mathrm{n}_{\mathrm{r}}}$ & -0.2116 & $\operatorname{rad}^{-1}$ & ? & 0.1873 & $\mathrm{rad}^{-1}$ & $\frac{?}{4}$ & 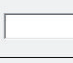 & $\mathrm{rad}^{-1}$ & $\frac{?}{4}$ \\
\hline $\mathrm{C}_{\mathrm{m}_{\mathrm{u}}}$ & 0.0015 & & $\mathrm{C}_{y_{\beta}}$ & -0.5358 & $\mathrm{rad}^{-1}$ & $\mathrm{C}_{\mathrm{D}_{\mathrm{h}}}$ & 0.0000 & $\operatorname{rad}^{-1}$ & & 0.1176 & $\mathrm{rad}^{-1}$ & & 0.0000 & & $\frac{1}{4}$ \\
\hline$C_{T_{x_{u}}}$ & 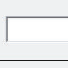 & & $?$ & -0.0380 & $\mathrm{rad}^{-1}$ & ? & 0.8466 & $\operatorname{rad}^{-1}$ & $?$ & 0.1176 & $\mathrm{rad}^{-1}$ & $\frac{?}{4}$ & 0.0000 & & $\frac{?}{4}$ \\
\hline $\mathrm{c}_{\mathrm{m}_{\mathrm{T}}}$ & & & $C_{n_{\beta}}$ & 0.1387 & $\mathrm{rad}^{-1}$ & 过c & -2.2301 & $\mathrm{rad}^{-1}$ & $\mathrm{C}_{1}$ & 0.0118 & $\mathrm{rad}^{-1}$ & \pm & -0.1393 & & $\frac{4}{4}$ \\
\hline $\mathrm{C}_{D_{\alpha}}$ & & $\operatorname{rad}^{-1}$ & $\frac{?}{4} \mathrm{C}_{\mathrm{n}} \mathrm{C}_{\mathrm{T}_{\mathrm{B}}}$ & Г & $\mathrm{rad}^{-1}$ & $\frac{?}{4} \mathrm{C}_{\mathrm{D}_{\mathrm{e}}}$ & 0.0000 & $\mathrm{rad}^{-1}$ & $\begin{array}{l}? \\
4 \\
4\end{array}$ & 0.0118 & $\mathrm{rad}^{-1}$ & empen & -0.1393 & & $\frac{?}{4}$ \\
\hline $\mathrm{C}_{\mathrm{L}_{\alpha}}$ & 4.8932 & $\mathrm{rad}^{-1}$ & $\frac{?}{y} \mathrm{c}_{\mathrm{y}_{\mathrm{\beta}}}$ & 0.0430 & $\mathrm{rad}^{-1}$ & ? & 0.3390 & $\mathrm{rad}^{-1}$ & $C_{n}$ & -0.0708 & $\mathrm{rad}^{-1}$ & $?$ & -0.1393 & & $\frac{?}{4}$ \\
\hline $\mathrm{C}_{\mathrm{m}_{\alpha}}$ & -0.8769 & $\mathrm{rad}^{-1}$ & $?$ & 0.0029 & $\mathrm{rad}^{-1}$ & $\frac{?}{4} \mathrm{C}_{\mathrm{L}_{\mathrm{o}_{\mathrm{O}}}}$ & 0.2213 & $\mathrm{rad}^{-1}$ & $\frac{?}{4} c_{n_{\delta_{r}}}$ & -0.0708 & $\mathrm{rad}^{-1}$ & 贯 & & & \\
\hline
\end{tabular}

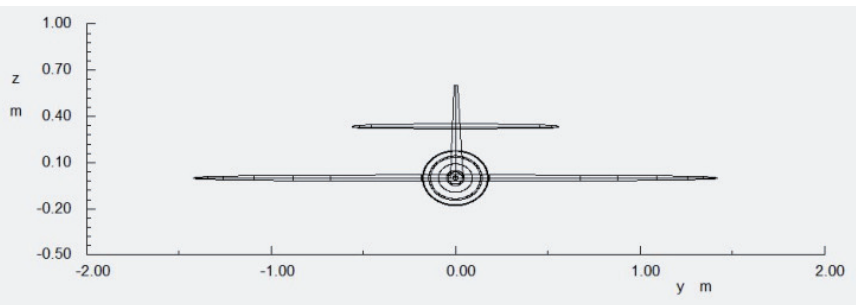

Fig. 4. Geometry of the JET-2

Fig. 5. Aerodynamic derivatives of the JET-2 plane 
The expressions that define coefficients of forces and moments are as follows:

- drag force:

- side force

$$
C_{D}=C_{D}(\alpha, M a)
$$

$$
C_{Y}=C_{Y}^{\beta} \beta+C_{Y}^{p} p \frac{l}{2 V}+C_{Y}^{r} r \frac{l}{2 V}+C_{Y}^{\delta_{a}} \delta_{a}
$$

- lift force:

$$
C_{L}=C_{L}(\alpha, M a)+C_{L}^{\dot{\alpha}} \frac{b_{a} \dot{\alpha}}{2 V}+C_{L}^{q} q \frac{b_{a} q}{2 V}+C_{L}^{\delta_{e}} \delta_{e}
$$

- rolling moment:

$$
C_{l}=C_{l}^{\beta} \beta+C_{l}^{p} \frac{l p}{2 V}+C_{l}^{r} \frac{l r}{2 V}+C_{l}^{\delta_{a}} \delta_{a}
$$

- pitching moment:

$$
C_{m}=C_{m}(\alpha, M a)+C_{m}^{\dot{\alpha}} \frac{b_{a} \dot{\alpha}}{2 V}+C_{m}^{q} \frac{b_{a} q}{2 V}+C_{m}^{\delta_{e}} \delta_{e}
$$

- yawing moment:

$$
C_{n}=C_{n}^{\beta} \beta+C_{n}^{p} \frac{l p}{2 V}+C_{n}^{r} \frac{l r}{2 V}+C_{n}^{\delta_{a}} \delta_{a} .
$$

Selected coefficients of the JET-2 airplane obtained using AAA software are shown in Fig. 5.

\section{Results of simulations}

Equations (2.1)-(2.8) have been employed in the preliminary study of characteristics of the dynamic stability of the JET-2 plane. Fig. 7-11 shows longitudinal reaction of the plane on impulse of elevator deflection $\delta_{\mathrm{e}}$. The airspeed was equal to $100 \mathrm{~m} / \mathrm{s}$. Duration of this impulse is $0.5 \mathrm{sec}$ and its amplitude is 2 degrees - Fig. 6 . We can see that all shown courses are damped. It means that the JET-2 plane has static and dynamic longitudinal stability. The separation between longitudinal and lateral motion are observed - lateral parameters $\beta, \Phi, \Psi$ are almost constant. The short-period mode of the longitudinal motion is strongly damped (Fig. 7, 8). This is most crucial for the stability of the plane. The phugoid mode is also damped (Fig. 9-11) and the period of this motion is identified as $49.5 \mathrm{sec}$.

To analyse the effect of flight conditions on the longitudinal modes similar simulations were done for various flight velocities. In all cases, all longitudinal motions were damped. Parameters of these motions were determined. Exemplary results are shown in Fig. 11 and 12. Both period and logarithmic decrement of damping are linearly dependent on flight velocity - they are closely proportional to airspeed. The period is in agreement with the simplified formula given by Lanchester for the period of phugoid motion $T_{\text {phug }} \approx \frac{\sqrt{2 \pi V}}{g}$.

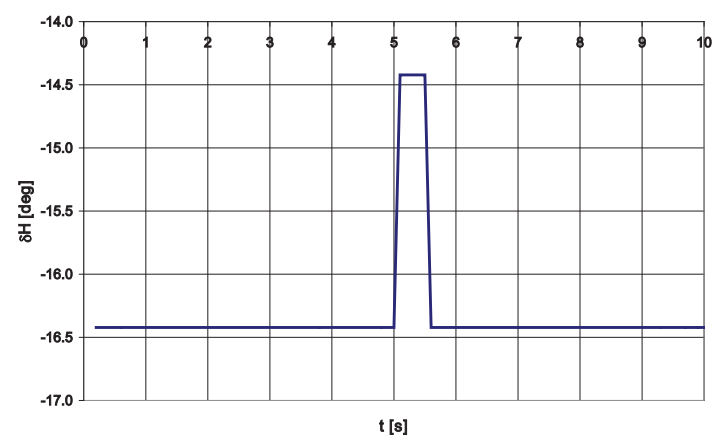

Fig. 6. Elevator impulse

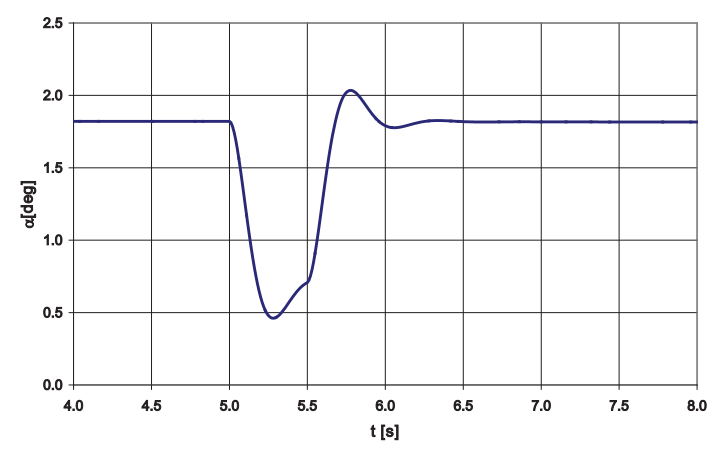

Fig. 7. Angle of attack vs. time-short-period mode 


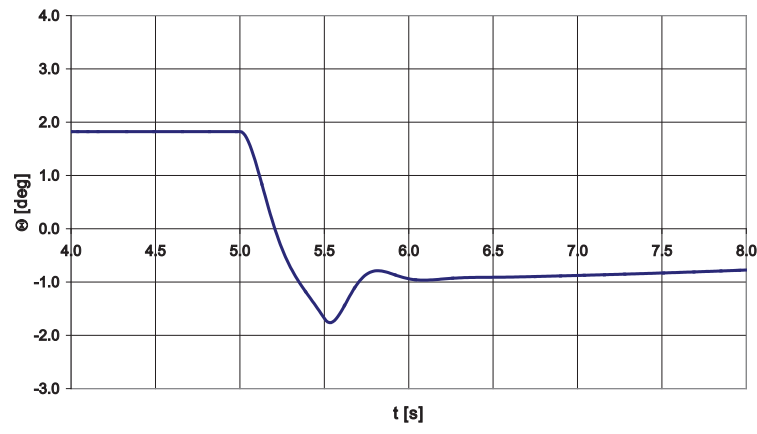

Fig. 8. Pitch angle vs. time-short-period mode

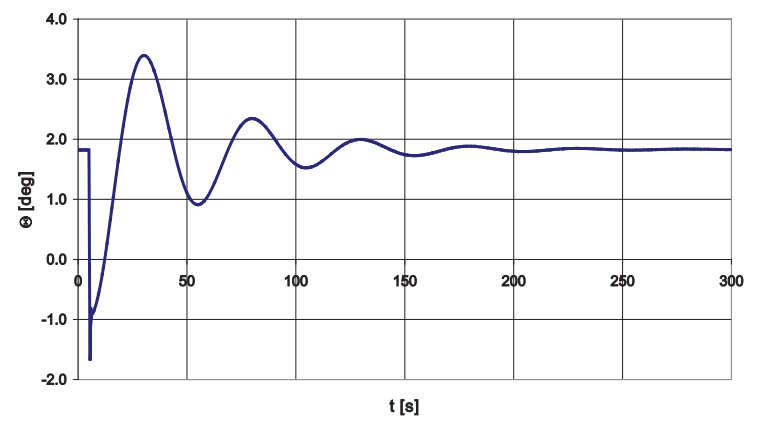

Fig. 10. Pitch angle vs. time - phugoid mode

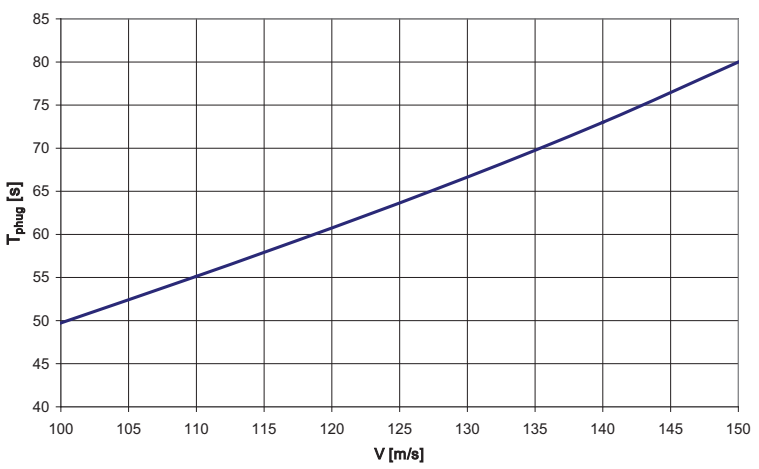

Fig. 11. Period of phugoid motion

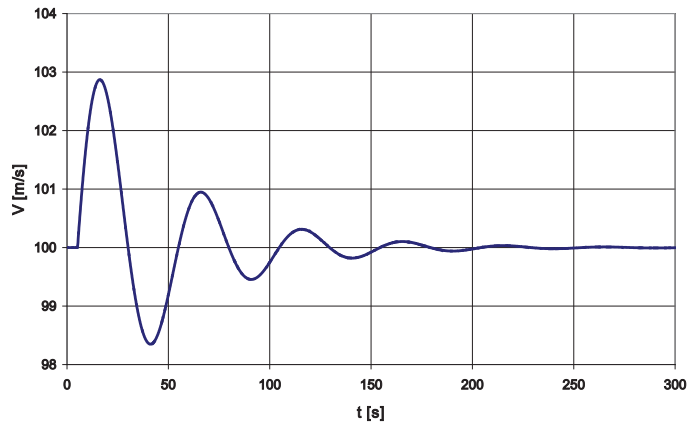

Fig. 9. Velocity vs. time - phugoid mode

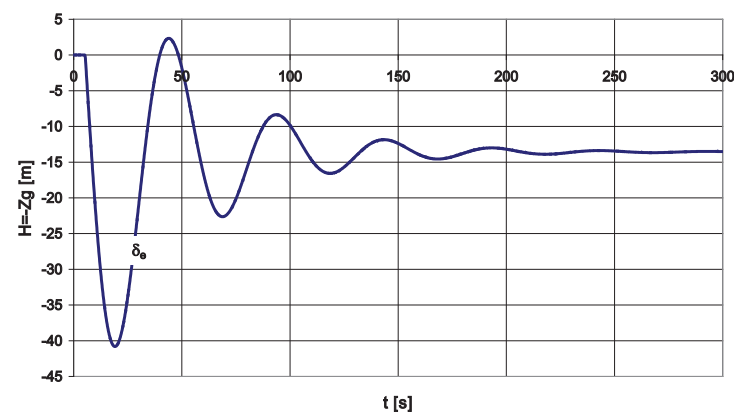

Fig. 11. Altitude of flight-phugoid mode

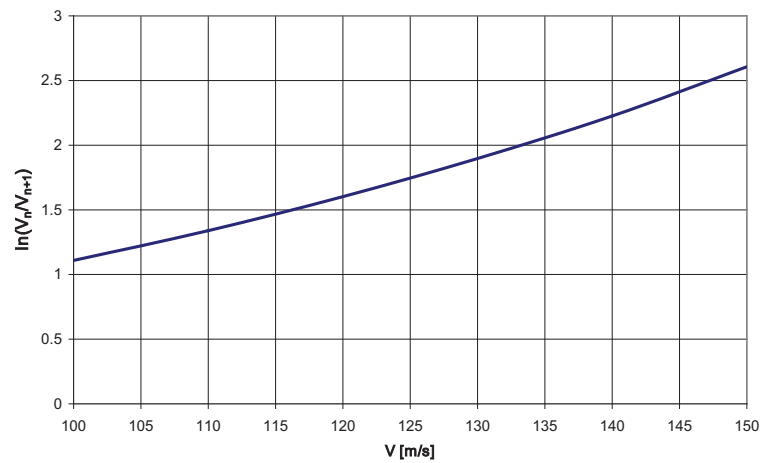

Fig. 12. Logarithmic decrement of damping for phugoid motion

Similar calculation were done to determine reaction of the JET-2 on impulse of aileron deflection $\delta_{\mathrm{a}}=2^{0}$. The profile of the impulse is the same as for the elevator. The airspeed is $100 \mathrm{~m} / \mathrm{s}$. Courses of lateral-directional parameters are shown in Fig. 14-17. In this case, reaction is different from for longitudinal motion. The dutch mode oscillations are damped - Fig. 14, 15, but the yaw rate stabilizes at a constant value - Fig. 16. The roll angle is almost constant - Fig. 17. It means that the plane performs a spiral motion with decreasing altitude. This is visible in Fig. 18 and 19.

Additional calculations have shown that for higher airspeed the spiral motion is damped. It is shown in Fig. 20 and 21 for the airspeed $150 \mathrm{~m} / \mathrm{s}$. We can see that the roll angle slowly decreases as well as the yaw rate.

\section{Conclusions}

The obtained results of simulations shown that the JET-2 UAV has sufficient dynamic properties to perform autonomous flights - longitudinal and lateral-directional short-period 
oscillations are damped by the drone. The phugoid mode is typical for classic designed airframe. Small spiral motion instability was obtained for low airspeed but this instability vanishes for growing flight velocity. It can be easy corrected by stabilized subsystem of an autopilot.

Presented results were calculated using theoretical mathematical model of the JET-2 spatial motion. In the future, this model will be validated and tuned on the basis of comparison between results of simulations and data recorded during test flights.

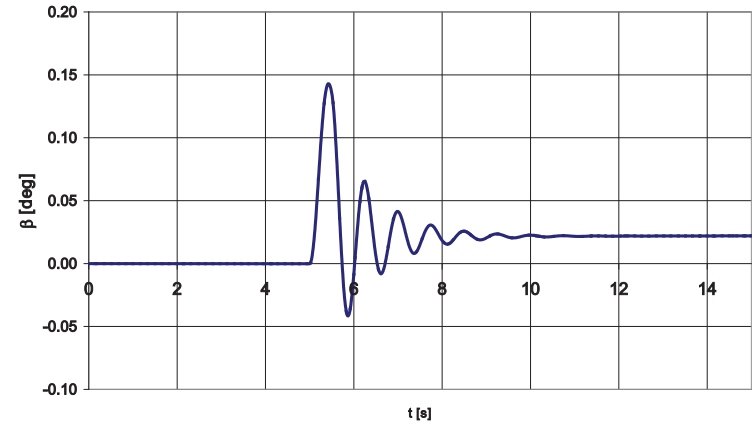

Fig. 14. Sideslip angle vs. time - dutch roll mode

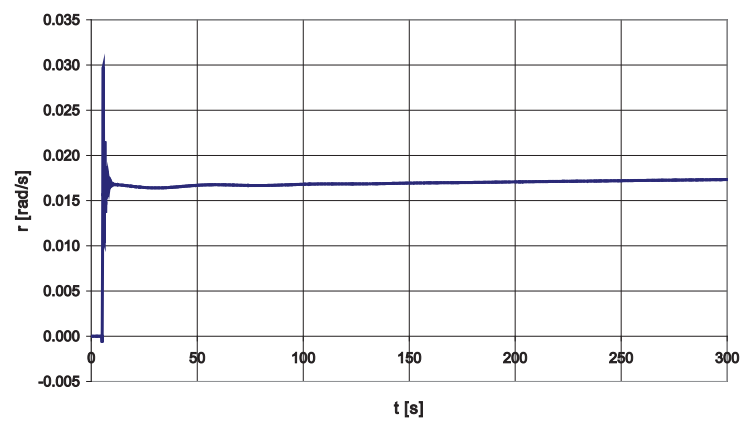

Fig. 16. Yaw rate vs. time - spiral mode

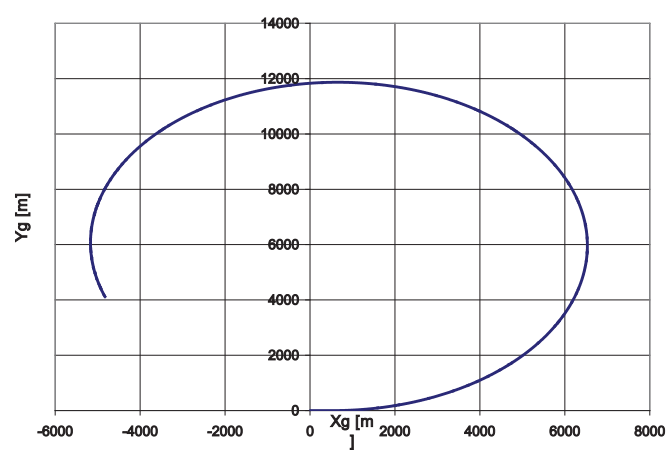

Fig. 18. Horizontal trajectory

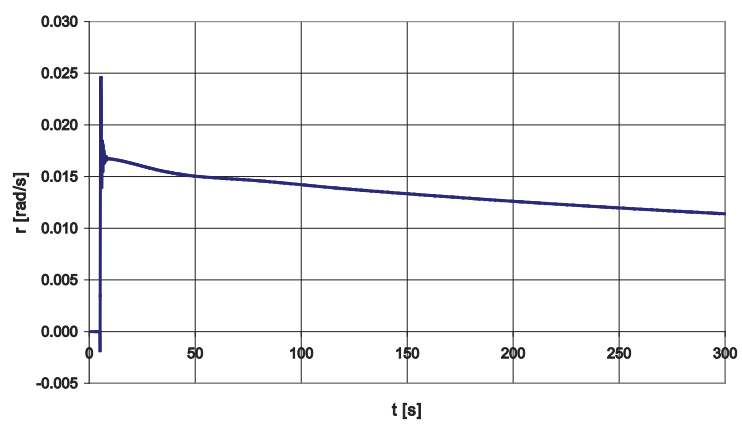

Fig. 20. Roll angle vs. time-spiral mode

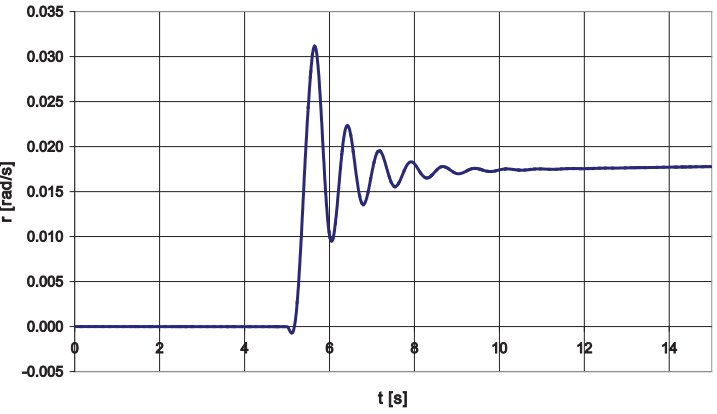

Fig. 15. Yaw rate vs, time - dutch roll mode

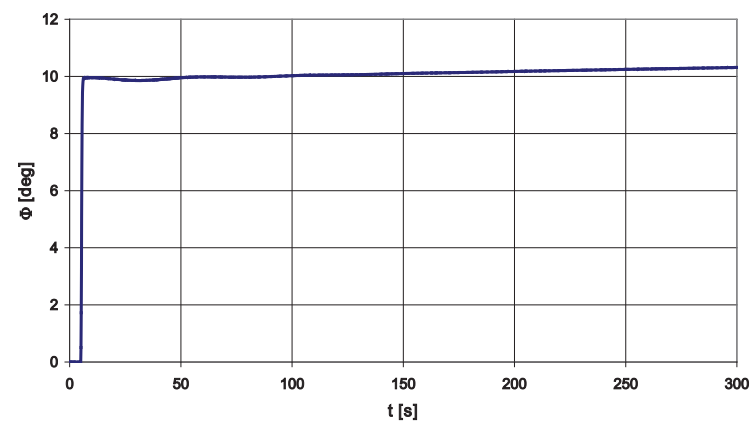

Fig. 17. Roll angle vs. time-spiral mode

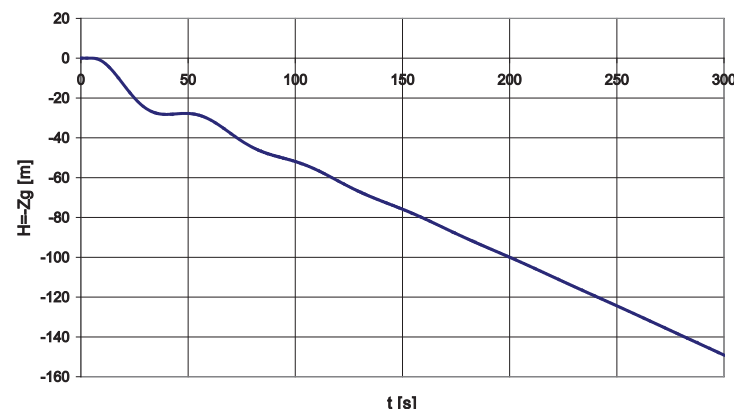

Fig. 19. Vertical trajectory

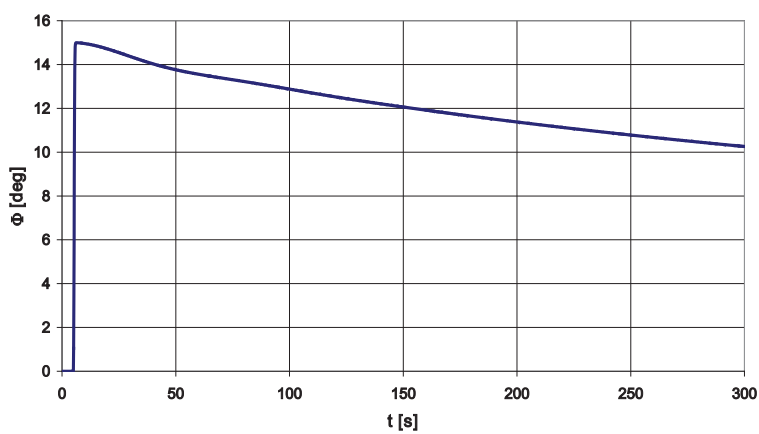

Fig. 21. Yaw rate vs. time-spiral mode 


\section{References}

[1] Advanced Aircraft Analysis ver.3.2, DAR Corporation, 2012.

[2] Etkin, B., Dynamics of Atmospheric Flight, Ed. John Wiley, New York, London, Sydney, Toronto 1972.

[3] Fiszdon, W., Mechanika lotu, Państwowe Wydawnictwo Naukowe, 1961.

[4] Kowaleczko, G., Zagadnienie odwrotne w dynamice lotu statków powietrznych, Wydawnictwo WAT, 2003.

[5] Ostoslawski, I., Aerodinamika samoleta, GIOP, 1957.

[6] Roskam, J., Airplane Design - Part 6 Preliminary Calculations of Aerodynamic, Thrust and Power Characteristics, RAEC, 1987.

[7] Stevens, B., Lewis, F., Aircraft Control and Simulation, Ed. John Wiley, New York, Chichester, Brisbane, Toronto, Singapore 1992.

\section{Nomenclature}

$b_{a} \quad-$ mean wing aerodynamic chord $[\mathrm{m}]$,

$C_{D}, C_{Y}, C_{L}$ - coefficients of drag, side and lift forces,

$C_{l}, C_{m}, C_{n}$ - coefficients of rolling, pitching and yawing moments,

$C_{i}^{j} \quad-$ dimensionless derivatives of $i$-th force/moment with respect to $j$-th variable,

$I_{x}, I_{y}, I_{z} \quad-$ moments of inertia about $x, y$ and $z$ axis $\left[\mathrm{kgm}^{2}\right]$,

$I_{x z} \quad-$ cross product of inertia $\left[\mathrm{kgm}^{2}\right]$,

$l \quad-$ wing span $[\mathrm{m}]$,

$L_{(.)}, M_{(.)}, N_{(.)}$- roll, pitch and yaw moments [kgm],

$m \quad-$ mass of aircraft $[\mathrm{kg}]$,

Oxyz - body-fixed reference frame,

$O x_{a} y_{a} z_{a} \quad$ - air-trajectory reference frame /velocity system of coordinates,

$O x_{g} y_{g} z_{g} \quad-$ plane-carried vertical frame,

$p, q, r \quad-$ roll, pitch and yaw rates [rad/s],

$P_{X a}, P_{X a}, P_{X a}-$ aerodynamic forces (drag, side force and lift) $[\mathrm{N}]$,

$S \quad-$ reference wing area $\left[\mathrm{m}^{2}\right]$,

$T \quad-$ thrust $[\mathrm{N}]$,

$V \quad-$ airspeed $[\mathrm{m} / \mathrm{s}]$,

$x_{g}, y_{g}, z_{g} \quad$ - trajectory coordinates,

$\alpha, \beta \quad-$ angles of attack and angle of sideslip,

$\delta_{\mathrm{a}}, \delta_{\mathrm{e}} \quad-$ angles of aileron and elevator deflection,

$\phi_{S} \quad-$ thrust line inclination angle [rad],

$\Theta, \Phi, \Psi \quad-$ pitch, roll and yaw angles,

$\rho \quad-$ air density $\left[\mathrm{kg} / \mathrm{m}^{3}\right]$. 